\section{Evaluation of a crop growth model for sweet potato over a set of agro-climatic conditions in India}

\author{
V. S. Santhosh Mithra ${ }^{1, *}$, Raji Pushpalatha ${ }^{1}$, \\ S. Sunitha ${ }^{1}$, James George ${ }^{1}$, P. P. Singh ${ }^{2}$, \\ R. S. Singh ${ }^{2}$, J. Tarafdar ${ }^{3}$, Surajit Mitra ${ }^{3}$, \\ Chandra Deo ${ }^{4}$, Sunil Pareek ${ }^{5,7}$, B. K. M. Lakshmi', \\ R. Shiny ${ }^{1}$ and G. Byju ${ }^{1}$ \\ ${ }^{1}$ ICAR-Central Tuber Crops Research Institute, \\ Thiruvananthapuram 695 017, India \\ ${ }^{2}$ Rajendra Agricultural University, Pusa, Samasthipur 848 125, India \\ ${ }^{3}$ Bidhan Chandra Krishi Vishwavidyalaya (BCKV), Kalyani 741252 , \\ India \\ ${ }^{4}$ Narendra Deva University of Agriculture and Technology, \\ Faizabad 224 229, India \\ ${ }^{5}$ Maharana Pratap University of Agriculture and Technology, \\ Udaipur 313 001, India \\ ${ }^{6}$ Shri Konda Laxman Telangana State Horticultural University, \\ Rajendra Nagar 500 030, India \\ ${ }^{7}$ Department of Agriculture and Environmental Sciences, \\ National Institute of Food Technology Entrepreneurship and \\ Management, Kundli, Sonipat 131 028, India
}

A study was conducted to evaluate the wider applicability of sweet potato growth model, 'SPOTCOMS' for simulating the phenology and yield over a set of agroclimatic conditions in India. The model simulated the phenology of the crop as a function of growing degree days. The genetic coefficients required for the model were estimated from the field experiments conducted with sweet potato variety, Sree Bhadra and other local varieties at the study locations. The model simulated the yield of the sweet potato well and the statistical indices calculated between the simulated and observed yields stated the reliability of the model simulations. The agreement index ( $D$-index) for Sree Bhadra ranged from 0.55 to 0.99 , and the $D$-index for local varieties ranged from 0.51 to 1.00 . The calculated values of normalized objective function ranged from 0.01 to 0.10 for Sree Bhadra and 0.00 to 0.22 for other local varieties, and indicated better agreement of simulated and observed yields. The normalized root mean square error ranged from $0.80 \%$ to $10.40 \%$ for Sree Bhadra and $0.00 \%$ to $22.44 \%$ for other varieties, and these results suggested the wider applicability of the model with excellent to good simulations. The model also simulated dry matter distribution in tubers pertaining to different stresses such as water, nitrogen and potassium. The study revealed that the simulation model 'SPOTCOMS' can be used for simulating the yield as well as to manage the stresses during the crop growth period and to optimize best management practices for the crop cultivation irrespective of the agroclimatic conditions.

Keywords: Crop phenology, calibration, growing degree days, SPOTCOMS, simulation.

\footnotetext{
*For correspondence. (e-mail: vssmithra@gmail.com)
}

SWEET potato is widely cultivated in tropical and subtropical areas and is considered an important part of the staple diet in many poor countries in Africa ${ }^{1}$. The tubers of sweet potato are rich in carbohydrate ${ }^{2}$, vitamins ${ }^{3}$ and proteins $^{1}$. Despite its potential for nutritional security, the industrial value of the crop can be exploited to ensure economic security of farmers in the context of climate change. In India, sweet potato is the third most important tuber crop after potato and cassava, and it is grown in almost all states except Jammu and Kashmir, Himachal Pradesh and Sikkim ${ }^{4}$. Realizing the gap between potential and actual yields at farm level in different agro-climatic conditions is important. It is tedious and laborious to quantify the yield response in different field conditions and controlled experiments. Crop simulation models represent simplified crop production systems consisting of nonlinear mathematical equations to provide a systematic analysis of the crop production system ${ }^{5}$. By considering the significance of this tuber crop as a staple as well as nutritional food, the present study evaluated the performance of 'SPOTCOMS - Sweet Potato Computer Simulation', a growth simulation model for the growth and yield of sweet potato ${ }^{6}$ over different agro-climatic conditions in India, to identify its wider applicability.

Study locations were selected such that they represent different agro-climatic conditions as well as the major sweet potato growing areas in India (Figure 1). The crop model 'SPOTCOMS' is the modification of the model

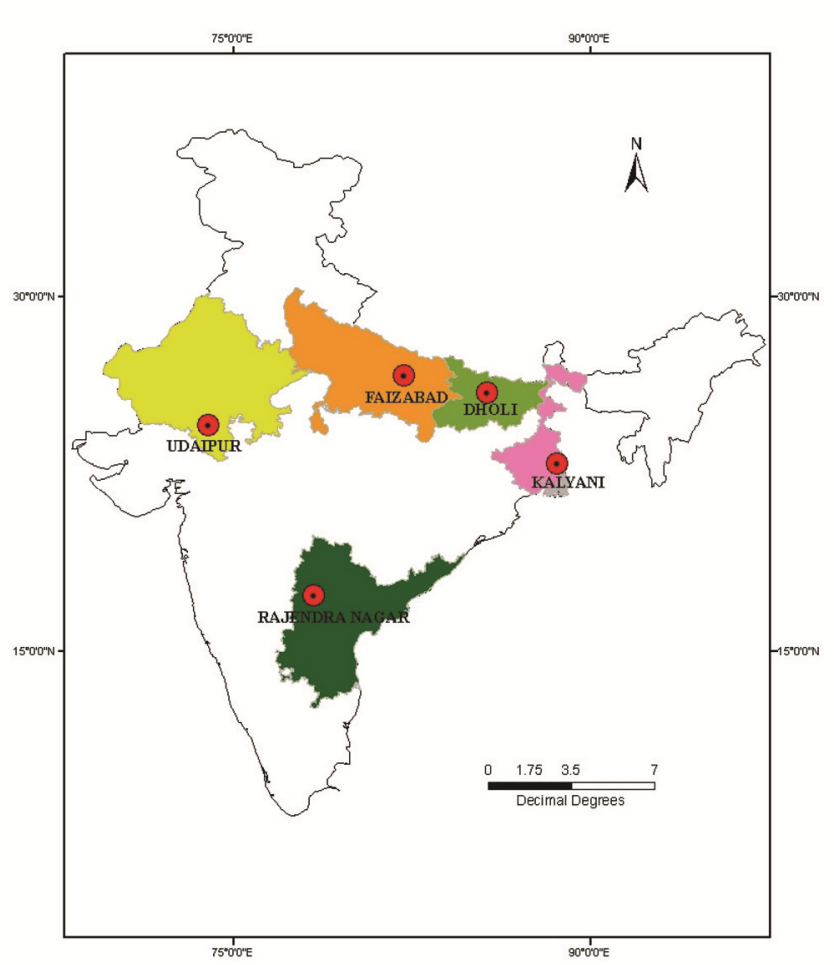

Figure 1. Map showing the study locations with different agroclimatic conditions.

CURRENT SCIENCE, VOL. 117, NO. 1, 10 JULY 2019 
RESEARCH COMMUNICATIONS

Table 1. Mean values of growth and yield parameters of Sree Bhadra based on field observations

\begin{tabular}{|c|c|c|c|c|c|c|c|}
\hline $\begin{array}{l}\text { Months after } \\
\text { planting }\end{array}$ & $\begin{array}{c}\text { Vine } \\
\text { length }(\mathrm{cm})\end{array}$ & $\begin{array}{c}\text { Internode } \\
\text { length }(\mathrm{cm})\end{array}$ & $\begin{array}{c}\text { No of leaves/ } \\
\text { plant }\end{array}$ & $\begin{array}{c}\text { No of tuberous } \\
\text { roots }\end{array}$ & $\begin{array}{c}\text { Weight of tuber/ } \\
\text { plant }(\mathrm{g})\end{array}$ & $\begin{array}{c}\text { Dry weight } \\
\text { above ground (g) }\end{array}$ & $\begin{array}{l}\text { Dry weight } \\
\text { below ground }(\mathrm{g})\end{array}$ \\
\hline 1 & 59 & 3 & 43 & & & & \\
\hline 3 & 116 & 4 & 193 & 5 & 145 & 44 & 54 \\
\hline 4 & 143 & 4 & 254 & 5 & 234 & 41 & 87 \\
\hline
\end{tabular}

Table 2. Observed values of growth parameters of local varieties of sweet potato

\begin{tabular}{|c|c|c|c|c|c|c|c|c|c|c|c|c|c|}
\hline \multirow{2}{*}{ 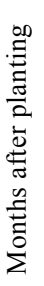 } & \multicolumn{5}{|c|}{ Vine length $(\mathrm{cm})$} & \multicolumn{4}{|c|}{ Internode length $(\mathrm{cm})$} & \multicolumn{4}{|c|}{ No. of leaves/plant } \\
\hline & $\begin{array}{l}: \overline{0} \\
\frac{1}{a}\end{array}$ & 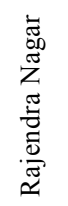 & 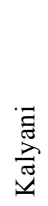 & 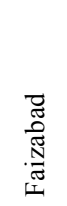 & 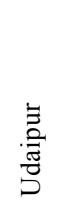 & $\begin{array}{l}\frac{\overline{0}}{\overline{0}} \\
\frac{1}{0}\end{array}$ & 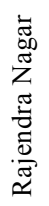 & 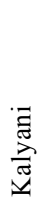 & 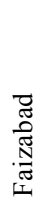 & $\begin{array}{l}\overline{7} \\
\frac{1}{0}\end{array}$ & 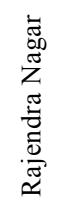 & $\frac{\vec{\Xi}}{\stackrel{\Xi}{\Xi}}$ & 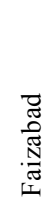 \\
\hline 1 & 58 & 52 & 7 & 76 & 40 & 2 & 3 & 3 & 4 & 19 & 91 & 21 & 52 \\
\hline 2 & 84 & 78 & 19 & 94 & 67 & 3 & 4 & 3 & 4 & 32 & 187 & 80 & 93 \\
\hline 3 & 99 & 106 & 42 & 108 & 122 & 3 & 3 & 4 & 4 & 56 & 302 & 225 & 241 \\
\hline 4 & 114 & 129 & 72 & 123 & 160 & 3 & 3 & 5 & 4 & 73 & 409 & 282 & 409 \\
\hline
\end{tabular}

'MADHURAM'7, where crop phenology is predicted based on vegetative developmental days and reproductive degree days. However, in SPOTCOMS, it is predicted as a function of growing degree days (GDD) which is the accumulated daily mean temperature since planting.

$$
\mathrm{GDD}_{d}=\sum_{i=1}^{d} T_{\text {mean }_{i}}-d \times T_{\text {base }}
$$

where $\mathrm{GDD}_{d}$ is the GDD after $d$ days of planting (DAP); $T_{\text {mean }_{i}}$ is the mean temperature on $i$ th $\mathrm{DAP}^{8}$. Optimum temperature and base temperature $\left(T_{\text {base }}\right)$ for the growth of sweet potato is calculated as $25^{\circ} \mathrm{C}$ and $8.1^{\circ} \mathrm{C}$ respective$1 y^{9}$. The model simulates the crop growth stages as initial, middle and third phases. The initial phase includes extensive growth of fibrous roots. Moderate growth rate of vines and extensive vine growth occur during the middle phase and this increases green leaf area and initiation of tubers. The third phase is characterized by very little growth of vines and fibrous roots, decrease in leaf area and initiation of tuber bulking. In the model, vine and tuber growth rates are calculated in terms of growing degree days and branching event is predicted as a function of number of leaves.

$$
\begin{gathered}
d \mathrm{VL}_{i}= \\
\log \left(\frac{d \mathrm{VL}_{i}^{\prime}+\frac{\left(\mathrm{DMV}_{i-1}-\mathrm{DMV}_{i-2}\right)}{\mathrm{DMV}_{i-2}} \times \frac{\left(\mathrm{VL}_{i-2}+\mathrm{BR}_{-} \mathrm{VL}_{i-2}\right)}{\mathrm{BR}_{i-2}}}{2}\right)
\end{gathered}
$$

where $d \mathrm{VL}_{i}$ is the rate of increase in vine length (VL) on $i$ th DAP; $\mathrm{DMV}_{i-1}$ and $\mathrm{DMV}_{i-2}$ the dry matter in vines on $(i-1)$ th and $(i-2)$ th DAP respectively; BR $\mathrm{VL}_{i-2}$ the length of branches on $(i-2)$ th $\mathrm{DAP} ; \mathrm{VL}_{i-2}$ the vine length of branches on $(i-2)$ th $\mathrm{DAP} ; \mathrm{BR}_{i-2}$ is the number of branches on $(i-2)$ th DAP

$$
\begin{aligned}
d \mathrm{VL}_{i}^{\prime} & =\frac{\operatorname{vlen} \times\left(\mathrm{GDD}_{i}-\mathrm{GDD}_{i-1}\right)}{f}, \quad i>1, \\
& =\frac{\text { vlen } \times \mathrm{GDD}}{f}, \quad i=0,
\end{aligned}
$$

where vlen is the parameter specific for the variety of sweet potato. Direct and diffused solar radiations are calculated separately and are used in calculating the gross photosynthesis in the model ${ }^{7}$. The number of leaves per plant is calculated by phenological growth rate and dry matter partitioned to the leaves. The effect of water stress on the crop growth is also computed ${ }^{10}$. Priestly and Taylor method is used for calculating reference evapotranspiration $\left(\mathrm{ET}_{0}\right)$. Apart from the yield estimation under water stress, the model can also assess the stress due to nitrogen and potassium deficiency. These nutrients are important inputs for increasing the number and weight of tubers. Nutrient stress on mean tuber weight is calculated using Mitscherlich's equation ${ }^{11}$.

The crop parameters required for calibration of the model were obtained from field experiments conducted during three seasons such as 2013-2014, 2014-2015 and 2015-2016 under the All India Coordinated Research Project on Tuber Crops in five locations. In each location, a high-yielding variety of sweet potato, Sree Bhadra (ICAR-CTCRI, Thiruvanathapuram) and one local variety popular among the farmers in that location were used for 
Table 3. Observed yield parameters of local varieties of sweet potato

\begin{tabular}{|c|c|c|c|c|c|c|c|c|c|c|c|c|c|c|c|c|c|}
\hline \multirow{2}{*}{ 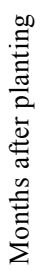 } & \multicolumn{5}{|c|}{ No. of tuberous roots } & \multicolumn{4}{|c|}{ Weight of tuber/plant $(\mathrm{g})$} & \multicolumn{4}{|c|}{ Dry weight above ground (g) } & \multicolumn{4}{|c|}{ Dry weight below ground $(\mathrm{g})$} \\
\hline & $\frac{\overline{0}}{\frac{1}{0}}$ & 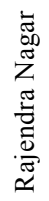 & 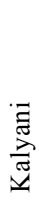 & 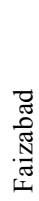 & 咅 & $\begin{array}{l}\overline{0} \\
\frac{1}{0}\end{array}$ & 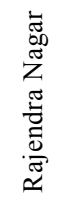 & $\frac{\vec{\Xi}}{\stackrel{\Xi}{\Xi}}$ & 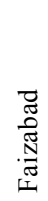 & $\begin{array}{l}\overline{\overline{0}} \\
\frac{1}{0}\end{array}$ & 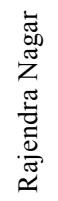 & $\frac{\vec{\Xi}}{\stackrel{\Xi}{\Xi}}$ & 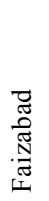 & $\frac{\overline{\bar{O}}}{\overline{0}}$ & 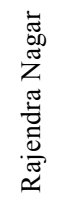 & $\frac{\vec{\Xi}}{\stackrel{\Xi}{\Xi}}$ & 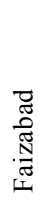 \\
\hline 2 & 4 & 5 & 5 & 3 & 5 & 47 & 111 & 72 & 5 & 10 & 112 & 0.4 & 17 & 12 & 100 & 0.2 & 4 \\
\hline 3 & 4 & 5 & 8 & 4 & 6 & 208 & 173 & 110 & 32 & 26 & 136 & 0.4 & 18 & 37 & 156 & 0.3 & 34 \\
\hline 4 & 5 & 5 & 8 & 4 & 5 & 312 & 258 & 208 & 60 & 36 & 119 & 1 & 21 & 58 & 205 & 0.5 & 60 \\
\hline
\end{tabular}

Table 4. Derived genetic coefficients of varieties for calibrating SPOTCOMS

\begin{tabular}{|c|c|c|c|c|c|c|}
\hline & & Kalyani & Udaipur & Faizabad & Dholi & Rajendra Nagar \\
\hline Plant parameters & Sree Bhadra* & BCSP-10 & $\mathrm{CO} 3-4$ & NSDP-65 & RS 92 & RNSP 1 \\
\hline Phs1gdd $\left({ }^{\circ} \mathrm{C}\right)$ & 515.25 & 503.35 & 514.85 & 495.6 & 611.45 & 534.3 \\
\hline phs2gdd $\left({ }^{\circ} \mathrm{C}\right)$ & 341.16 & 313.35 & 358.2 & 289.5 & 400.35 & 376.75 \\
\hline Vlen $\left(\mathrm{cm}^{\circ} \mathrm{C}^{-1}\right)$ & 0.076 & 0.0628 & 0.080 & 0.052 & 0.065 & 0.0644 \\
\hline Tgrate $\left({ }^{\circ} \mathrm{C}^{-1}\right)$ & 0.001 & 0.0048 & 0.0025 & 0.0032 & 0.002 & 0.0026 \\
\hline Leaf factor $\left({ }^{\circ} \mathrm{C}^{-1}\right)$ & 0.0244 & 0.0374 & 0.0230 & 0.0175 & 0.0116 & 0.0193 \\
\hline Leaf area factor $\left(\mathrm{cm}^{2}\right)$ & 72.27 & 59.119 & 122.814 & 52.070 & 85.812 & 141.45 \\
\hline Leaf area $\left(\mathrm{cm}^{2}\right)$ & 44.112 & 32.15 & 73.05 & 34.35 & 64.9 & 90.2 \\
\hline Row $\times$ row $(\mathrm{cm})$ & 60 & 60 & 60 & 60 & 60 & 60 \\
\hline Plant $\times$ plant $(\mathrm{cm})$ & 20 & 20 & 20 & 20 & 20 & 20 \\
\hline
\end{tabular}

*Values of Sree Bhadra represent the mean values from five study centres; Phs 1 gdd is GDD at 4 weeks after planting under tropical conditions and 9.5 weeks under temperate conditions; phs2gdd is GDD between 4 and 7 weeks after planting under tropical conditions; Vlen is the vine length; Tgrate is the tuber growth rate; br_gap is the branch gap.

deriving crop parameters for calibrating the SPOTCOMS. A variety RS-92 was used as local trial crop in Dholi. RNSP-1, BCSP-10, NSDP-65 and CO 3-4 were used as local varieties in Rajendra Nagar, Kalyani, Faizabad and Udaipur respectively. The growth parameters of Sree Bhadra were the mean of values obtained from all the experimental locations (Table 1), whereas the local variety used in each location was different and hence the value as such was used (Tables 2 and 3). The crop coefficients for calibrating the model were derived from these observed growth and yield parameters and were listed in Table 4.

The simulated and observed yields were listed in Table 5. The model performance was evaluated using agreement index $(D \text {-index })^{12}$, normalized objective function $(\mathrm{NOF})^{13}$ and normalized mean square error (NRMSE) ${ }^{14}$. The value of $D$-index ranges from 0 to 1 , and closer the index value to 1 , better is the agreement between the two variables that are being compared. NOF value equal to 0 indicates perfect match between observed and simulated yields. NRMSE gives a measure (\%) of the relative difference of simulated and observed data. The simulation is considered excellent with a NRMSE of less than $10 \%$, good if the value is between $10 \%$ and $20 \%$, fair if it is more than $20 \%$ and less than $30 \%$, and poor if the value is greater than $30 \%$ (ref. 15).

The $D$-index calculated for Sree Bhadra in the study locations ranged from 0.60 (Dholi) to 0.99 (Faizabad) indicating better model simulations with the observations. The $D$-index values of local varieties in the study locations ranged from 0.43 (Rajendra Nagar) to 1.00 (Dholi). The simulated yield of the variety RS92 in Dholi was $29.4 \mathrm{tha}^{-1}$, same as that of the observation, which showed a $D$-index value of 1 . The calculated $D$-index values in all the five locations insist the suitability of the model for simulating the crop phenology irrespective of the agroclimatic conditions. NOF values calculated for Sree Bhadra were close to zero in all locations $(0.01$ to 0.10$)$. NOF value (0.00) calculated for the local variety at Dholi indicated perfect model simulation. NOF values also indicated the model suitability to simulate crop yields. The value of NRMSE for Sree Bhadra ranged from 0.80 to $10.39 \%$ (excellent to good simulations). The NRMSE values for local varieties ranged from 0.66 to 22.44 respectively.

The simulations of local varieties were found to be excellent in three locations (Dholi, Faizabad and Udaipur), good (Kalyani) and fair (Rajendra Nagar) in the other two locations. These results also revealed the wider applicability of the model for simulating the phenology and yield of sweet potato. The model also simulated total dry matter production in tubers under different stresses such as water, nitrogen and potassium (Table 6). These stress factors were analysed and used for managing during the crop growth, to obtain the potential yield. Hence, 
RESEARCH COMMUNICATIONS

Table 5. Model performance with respect to different criteria

\begin{tabular}{|c|c|c|c|c|c|}
\hline Locations & Observed yield $\left(\mathrm{t} \mathrm{ha}^{-1}\right)$ & Simulated yield $\left(\mathrm{t} \mathrm{ha}^{-1}\right)$ & $D$-index & NOF & NRMSE \\
\hline \multicolumn{6}{|l|}{ Sree Bhadra } \\
\hline Kalyani & 22.33 & 19.86 & 0.82 & 0.05 & 5.15 \\
\hline Udaipur & 23.45 & 25.24 & 0.88 & 0.04 & 4.11 \\
\hline Faizabad & 24.83 & 25.2 & 0.99 & 0.01 & 0.80 \\
\hline Dholi & 19.1 & 22.84 & 0.60 & 0.10 & 10.39 \\
\hline Rajendra Nagar & 20 & 20.56 & 0.94 & 0.01 & 1.47 \\
\hline \multicolumn{6}{|l|}{ Local varieties } \\
\hline Kalyani & 20 & 25.77 & 0.51 & 0.15 & 15.39 \\
\hline Udaipur & 35.43 & 39.64 & 0.65 & 0.06 & 6.19 \\
\hline Faizabad & 26.75 & 26.42 & 0.99 & 0.01 & 0.66 \\
\hline Dholi & 29.4 & 29.4 & 1.00 & 0.00 & 0.00 \\
\hline Rajendra Nagar & 19.3 & 27.38 & 0.43 & 0.22 & 22.44 \\
\hline
\end{tabular}

Table 6. Simulated yields for crop varieties under different stresses

\begin{tabular}{|c|c|c|c|c|c|c|c|c|}
\hline Locations & Varieties & $\begin{array}{l}\text { Yield under } \\
\text { DMTw } \\
\left(\mathrm{t} \mathrm{ha}^{-1}\right)\end{array}$ & $\begin{array}{l}\text { Yield under } \\
\text { DMTk } \\
\left(\mathrm{t} \mathrm{ha}^{-1}\right)\end{array}$ & $\begin{array}{l}\text { Yield under } \\
\text { DMTn } \\
\left(\mathrm{t} \mathrm{ha}^{-1}\right)\end{array}$ & $\begin{array}{l}\text { Yield under } \\
\text { DMTwk } \\
\left(\mathrm{t} \mathrm{ha}^{-1}\right)\end{array}$ & $\begin{array}{l}\text { Yield under } \\
\text { DMTwn } \\
\left(\mathrm{t} \mathrm{ha}^{-1}\right)\end{array}$ & $\begin{array}{l}\text { Yield under } \\
\text { DMTkn } \\
\left(\mathrm{t} \mathrm{ha}^{-1}\right)\end{array}$ & $\begin{array}{l}\text { Actual yield } \\
\text { DMTwkn } \\
\left(\mathrm{t} \mathrm{ha}^{-1}\right)\end{array}$ \\
\hline \multirow[t]{2}{*}{ Kalyani } & Sree Bhadra & 42.05 & 31.85 & 57.07 & 20.51 & 40.43 & 30.19 & 19.86 \\
\hline & BCSP-10 & 51.53 & 39.31 & 67.91 & 27.99 & 48.66 & 35.03 & 25.77 \\
\hline \multirow[t]{2}{*}{ Udaipur } & Sree Bhadra & 53.94 & 27.6 & 49.1 & 27.6 & 49.1 & 25.24 & 25.24 \\
\hline & $\mathrm{CO} 3-4$ & 85.27 & 42.87 & 79.31 & 42.87 & 79.3 & 39.64 & 39.64 \\
\hline Faizabad & NSDP-65 & 53.06 & 32.66 & 55.5 & 27.98 & 48.9 & 30.6 & 26.42 \\
\hline \multirow[t]{2}{*}{ Dholi } & Sree Bhadra & 44.43 & 24.38 & 41.01 & 24.38 & 41.01 & 22.84 & 22.84 \\
\hline & RS 92 & 56.1 & 30.81 & 52.05 & 30.81 & 52.05 & 29.4 & 29.4 \\
\hline \multirow[t]{2}{*}{ Rajendra Nagar } & Sree Bhadra & 41.58 & 22.88 & 40.46 & 22.52 & 39.67 & 21.5 & 20.56 \\
\hline & RNSP 1 & 60.74 & 31.76 & 60.42 & 29.36 & 55.96 & 30.14 & 27.38 \\
\hline
\end{tabular}

DMT, Dry matter in tuber; DMTw, DMT due to water stress; DMTk, DMT due to potassium stress; DMTn, DMT due to nitrogen stress; DMTwk, DMT due to water and potassium stress; DMTwn, DMT due to water and nitrogen stress; DMTkn, DMT due to potassium and nitrogen stress; DMTwkn, DMT due to water, potassium and nitrogen stress.

the output of the model can be used for optimizing best management practices for sweet potato cultivation. In conclusion, SPOTCOMS can simulate growth and yield of sweet potato irrespective of the agro-climatic conditions. However, model simulations under stress conditions need to be further validated with field experiments.

1. Muktar, A. A., Tanimu, B., Anurah, U. L. and Babaji, B. A., Evaluation of the agronomic characters of sweet potato varieties grown at varying levels of organic and inorganic fertilizer. World $J$. Agric. Sci., 2010, 6(4), 370-373.

2. Ustimenko, C. G. V. and Bakumovsky, Plants Growing in Tropics and Subtropics, Mir Publishers, 1982.

3. Villareal, R. L., Sweet potato in tropics:progress and problems. In Proceedings of the 1st International Symposium on Sweet Potato (eds Villereal, R. L. and Griggs, T. D.), AVRDC, Taiwan, China, 1982, pp. 3-15.

4. Edison, S., Vinayaka Hegde, Makeshkumar, T., Srinivas, T., Suja, G. and Padmaja, G., The sweet potato in the Indian Sub-Continent In The Sweet Potato, Springer, Netherlands, 2009, pp. 391-414.

5. Ritchie, J. T., Specifications of the ideal model for predicting in crop yields. In Climate Risk in Crop Production: Models and Management for the Semiarid Tropics and Subtropics (eds Muchow, R. C. and Bellamy, J. A.), CAB International, Wallingford, 1989, pp. 97-122.

6. Santhosh Mithra, V. S. and Somasundharam, K., A model to simulate sweet potato growth. World Appl. Sci. J., 2008, 4(4), 568-577.
7. Somasundharam, K., Santhosh Mitra and Madhuram, V. S., A simulation model for sweet potato growth. World J. Agric. Sci., 2008, 4(2), 241-254.

8. Jones, J. W. et al., The DSSAT cropping system model. Eur. J. Agron., 2003, 18, 235-265.

9. Penning de Vries, F. W. T., Jansen, D. M., Tenberge, H. F. N. and Bakema, A., Simulation of ecpohysiological process of growth in several annual crops. IRRILosBunosPudoc, Wageningen, 1989.

10. Allen, R. G., Pereira, L. S. and Smith, M., Crop evapotranspiration-guidelines for computing crop water requirements. FAO irrigation and drainage paper, 1998, p. 56.

11. Biswas, T. D. and Mukherjee, S. K., Soil fertility and fertilizer use. In Textbook of Soil Science, Tata McGraw Hill, 1994, pp. 22-285.

12. Willmott, C. J. et al., Statistic for the evaluation and comparison of the models. J. Geophys. Res., 1985, 90, 8995-9005.

13. Ahuja, L. R., Ma, L. and Howell, T. A., Agricultural system models. In Field Research and Technology Transfer, CRC Press, New York, USA, 2002.

14. Jamieson, P. D., Porter, J. R. and Wilson, D. R., A test of computer simulation model ARC wheat on wheat crops grown in New Zealand. Field Crops Res., 1991, 27, 337-350.

15. Loague, K. and Green, R. E., Statistical and graphical methods for evaluating solute transport models: overview and application. J. Contam. Hydrol., 1991, 7, 51-73.

Received 17 January 2019; revised accepted 30 March 2019

doi: $10.18520 / \mathrm{cs} / \mathrm{v} 117 / \mathrm{i} 1 / 110-113$ 